\title{
Quality Control Monitoring \& Evaluation of Bilirubin, Alkaline Phosphates and Inter-Laboratory Assessment of two Hospitals in North Central Nigeria
}

\author{
Stephen I. Audu ${ }^{*}$, Deborah O. Inyanda ${ }^{2}$, Amukali, $\mathrm{O}^{3}$, Agbeyo O.A ${ }^{2}$, H.D. Ezeofor ${ }^{4}$, \\ Robinson Anyebe ${ }^{5}$ \\ ${ }^{I}$ Department of Chemistry, Benue State University, Makurdi, Nigeria \\ ${ }^{2}$ Department of Science Laboratory Technology, Federal Polytechnic, Nasarawa, \\ ${ }^{3}$ Department of Geography \& Environmental Management, Niger Delta University, Bayelsa, Nigeria \\ 4Epidemiology Dept. London school of Hygiene and Tropical Medicine, \\ ${ }^{5}$ Department of Chemical Pathology, Benue State University Teaching Hospital, Makurdi, Nigeria
}

*Corresponding Author: Stephen I. Audu, Department of Chemistry, Benue State University, Makurdi, Nigeria

\begin{abstract}
Laboratory quality control is designed to detect, reduce, and correct deficiencies in a laboratory's internal analytical process prior to the release of patient results, in order to improve the quality of the results reported by the laboratory. The study was done to assess the quality control monitoring and evaluation of Bilirubin \& alkaline phosphates and also for inter-laboratory studies of some electrolytes in Nisa Premier Hospital Abuja and the Benue State University Teaching Hospital Makurdi, North central Nigeria. The quality control monitoring \& evaluation of Bilirubin and Alkaline phosphates were conducted for two consecutive months using the spectrophotometer (kenza240 TXbiolabo France), and the inter laboratory studies was done and the following electrolytes $\left(\mathrm{K}^{+}, \mathrm{Na}^{+}, \mathrm{Cl}, \mathrm{TCO}_{2}{ }^{-}\right)$were determined in blood samples at both locations. At both locations determination was performed using Ion Selective Analyzer AC9900 (Audicom, China).The results of quality control showed that Trends (loss of reliability) and shifts (abrupt changes in the control mean) were noted in the results of this study, there were two major trends in July and more shifts in the month of August than in the month of July for bilirubin and two violations of the Westgard Rule for Alkaline phosphates. The results of inter-laboratory assessment of Electrolytes shows a great difference in the mean values of $K^{+}$between the laboratories in NiSA (3.29 \pm 0.40$)$ and BSUTH (12.23 \pm 4.65$)$ but imprecision was within acceptable performance. This is similar for all other analytes $\left({ }^{+}{ }^{+}, \mathrm{TCO}_{2}^{-}\right)$with exception of $\mathrm{Cl}$ - which clearly indicated marginal performance. The results of the study shows that both imprecision and bias exist between both laboratories but imprecision was within Acceptable performance.
\end{abstract}

Keywords: Quality Control, Bilirubin, Alkaline phosphates, Electrolytes, Inter-laboratory, Westgard Rule

\section{INTRODUCTION}

In an inter-laboratory experiment, different laboratories determine some characteristic, e.g. the concentration of an analyte in one or various homogeneous samples under documented conditions. Several subtypes of inter-laboratory studies can be distinguished. Collaborative trials or method performance studies are used to test the performance (generally the precision) of a single analytical method. A standard method, which is routinely used in several laboratories, can also be examined collaboratively to test for a possible bias of either the method (method bias) or the laboratories (laboratory bias) that routinely use it [1]. Quality control is a measure of precision, or how well the measurement system reproduces the same result over time and under varying operating conditions. Laboratory quality control material is usually run at the beginning of each shift, after an instrument is serviced, when reagent lots are changed, after calibration, and whenever patient results seem inappropriate [2] Interpretation of quality control data involves both graphical and statistical methods. Quality control data is most easily visualized using a Levey-Jennings charts. The dates of analyses are plotted along the $\mathrm{X}$-axis and control values are plotted on the $\mathrm{Y}$-axis. The mean and one, two, and 
three standard deviation limits are also marked on the Y-axis. Inspecting the pattern of plotted points provides a simple way to detect increased random error and shifts or trends in calibration [3].Rules, such as the Westgard rules can be applied to see whether the results from the samples when the control was done can be released, or if they need to be rerun. The formulation of Westgard rules were based on statistical methods. Westgard rules are commonly used to analyse data in Shewhart control charts. Westgard rules are used to define specific performance limits for a particular assay and can be used to detect both random and systematic errors. Westgard rules are programmed in to automated analyzers to determine when an analytical run should be rejected. These rules need to be applied carefully so that true errors are detected while false rejections are minimized. The rules applied to high volume chemistry and hematology instruments should produce low false rejection rates [4,5,6].

Bilirubin is an endogenous, tetrapyrrolic compound, [7] a reductase catalysed product of biliverdin; the cleavage of alpha-methene bridge of heme by membrane-bound hemeoxygenase produces biliverdin as one of the breakdown products [8]. The primary mammalian, "yellow", bile pigment consists of unconjugated bilirubin (UCB), similar to many weakly-polar and poorly-soluble compounds; UCB is transported in blood tightly bound to albumin, with $<0.01 \%$ of total serum bilirubin (TSB) circulating as free bilirubin in an unbound form [7]. This is the portion of UBC that is responsible for its diffusion into tissues and consequently for its beneficial as well as toxic effects on cells [9]. In the liver, bilirubin is conjugated with glucuronic acid by the enzyme glucuronyl transferase, making it soluble in water: the conjugated version is the main form of bilirubin present in the "direct" bilirubin fraction. Much of it goes into the bile and thus out into the small intestine. Though most bile is reabsorbed in the terminal ileum to participate inenterrohepatic circulation, conjugated bilirubin is not absorbed and instead passes into the colon [10,11]. The alkaline phosphatase test (ALP) is used to help detect liver disease or bone disorders. In conditions affecting the liver, damaged liver cells release increased amounts of ALP into the blood. This test is often used to detect blocked bile ducts because ALP is especially high in the edges of cells that join to form bile ducts. If one or more of them are obstructed, for example by a tumor, then blood levels of ALP will often be high [12].However, deviations from the true results of this analytes can cause a lots of chronic diseases such as hepatitis, liver disorders, jaundice and kidney malfunctions, hence accurate and reliable quality control monitoring and evaluation is needed prior to the release of patients results to facilitate reliable clinical decision. Electrolytes are minerals that have many functions in the body including maintaining water balance, helping your muscles (including your heart) contract and relax and helping transmit nerve impulses. The most common electrolytes are sodium, potassium, and chloride, which are lost in sweat along with water[13 ].In physiology, the primary ions of electrolytes are sodium $\left(\mathrm{Na}^{+}\right)$, patassium $\left(\mathrm{K}^{+}\right)$, calcium $\left(\mathrm{Ca}^{2+}\right)$, magnesium $\left(\mathrm{Mg}^{2+}\right)$, chloride $\left(\mathrm{Cl}^{-}\right)$, hydrogen phosphate $\left(\mathrm{HPO}_{4}{ }^{2-}\right)$, and hydrogen carbonate $\left(\mathrm{HCO}_{3}{ }^{-}\right)$. The electric charge symbols of plus $(+)$and minus (-) indicate that the substance is ionic in nature and has an imbalanced distribution of electrons, the result of chemical dissociation. Sodium is the main electrolyte found in extracellular fluid and potassium is the main intracellular electrolyte, both are involved in fluid balance and blood pressure control [13]

\section{MATERIALS AND METHODS}

\subsection{Study Setting and Design}

The study was carried out at the Bioscience Laboratories at Nisa Premier Hospital (Nisa), Jabi district and the Chemical pathology Laboratory at the Benue State University Teaching Hospital (BSUTH), Makurdi, Nigeria. These laboratories provide services to inpatients, outpatients and patients on emergency. The study was approved by the Health Research and Ethics Committee of the Hospitals.

\subsection{Quality Control}

Quality control monitoring and evaluation of bilirubin and alkaline phosphateswere conducted using Biolabo Extrator-N (Normal) and Biolabo Extratol-P (Pathological) by gently mixing 5mL of Extrator-N buffer with lypholized Bovine Serum and inserting into the spectrophotometer Kenza240 TX and results collated for two consecutive months of July and August 2016. The quality control product which is a patient-like material ideally made from human serum, urine or spinal fluid. The control products were in the form of liquid or freeze dried (lyophilized) material and are composed of one or more constituents (analytes) of known concentration. 
Quality Control Monitoring \& Evaluation of Bilirubin, Alkaline Phosphates and Inter-Laboratory Assessment of two Hospitals in North Central Nigeria

\subsection{Determination of Electrolytes}

The following electrolytes $\left(\mathrm{K}^{+}, \mathrm{Na}^{+}, \mathrm{Cl}^{-} \mathrm{TCO}_{2}^{-}\right)$were determined in blood samples collected randomly at both locations. At both locations determination was performed using the same instrumentation; Ion Selective Analyser AC9900 (Audicom, China).The principle of the measurement consist of blood Samples been centrifuged to get the serum, the serum was then separated with pipette and $1 \mathrm{~mL}$ of the sample was inserted directly in the Ion Selective Analyser AC9900 (Audicom, China) and electrolytes concentrations were recorded.

\subsection{Statistical Analysis}

Data collected were collated on Microsoft Excel spread sheet and analysis was done using Analyse-it ( $)$ Version 4.6, (Analyse-it Leeds, UK) [14]. The Two of the most important metrics of an inter laboratory program are the coefficient of variation ratio (CVR) and standard deviation index (SDI), which are consensus-based metrics of imprecision and bias, respectively were used, and the LeveyJeneys chart was used for quality control. The software supports the latest CLSI and industryrecognised protocols, enables the analyst to validate, verify and demonstrate analytical accuracy, precision, linearity, reference intervals, and diagnostic performance [14]

\section{RESUlts}

The results of quality control showed that Trends (loss of reliability) and shifts (abrupt changes in the control mean) were noted in the results of this study, there were two major trends in July and more shifts in the month of August than in the month of July for bilirubin and two violations of the Westgard Rule for Alkaline phosphates. Two control values were out of control and violated the $1_{2} \mathrm{~s}$ Westgard rule for both bilirubin and Alkaline phosphates in the month of July and August.The result of inter laboratory study for electrolytes analyses (Table 1) shows a great difference in the mean

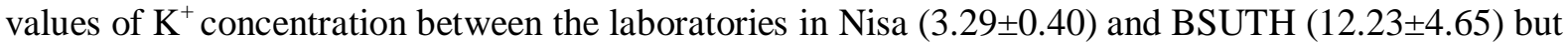
imprecision was within acceptable performance.

This is similar for all other analytes $\left(\mathrm{Na}^{+}, \mathrm{TCO}_{2}{ }^{-}\right)$, with exception of $\mathrm{Cl}^{-}$which clearly indicated "Marginal performance", indicating a corrective action to be taken for measurement imprecision.

Table1. Electrolytes analysis of interlaboratory study

\begin{tabular}{|r|r|r|r|r|r|r|r|r|r|r|}
\hline $\begin{array}{r}\text { Electrolyte } \\
\text { Parameter }\end{array}$ & Laboratory & Mean & SD & CV & $\begin{array}{r}\text { CVR_- } \\
\text { Nisa }\end{array}$ & $\begin{array}{r}\text { CVR } \\
\text { BSUTH }\end{array}$ & $\begin{array}{r}\text { Average } \\
\text { CRV }\end{array}$ & $\begin{array}{r}\text { SDI_ } \\
\text { Nisa }\end{array}$ & $\begin{array}{r}\text { SDI_ } \\
\text { BSUTH }\end{array}$ & $\begin{array}{r}\text { Average } \\
\text { SDI }\end{array}$ \\
\hline $\mathrm{K}^{+}$ & Nisa & 3.92 & 0.40 & 0.103 & & & & & & \\
\hline & BSUTH & 12.23 & 4.65 & 0.380 & 0.27 & 0.29 & 0.28 & 1.29 & 2.48 & 1.89 \\
\hline $\mathrm{Na}^{+}$ & Nisa & 139.53 & 1.99 & 0.014 & & & & & & \\
\hline & BSUTH & 133.00 & 4.68 & 0.035 & 0.40 & 0.47 & 0.44 & 111.09 & 62.73 & 86.91 \\
\hline $\mathrm{Cl}^{-}$ & Nisa & 99.45 & 4.48 & 0.045 & & & & & & \\
\hline & BSUTH & 104.71 & 1.85 & 0.018 & 2.68 & 2.56 & 2.63 & 42.74 & 82.53 & 62.63 \\
\hline $\mathrm{TCO}_{2}^{-}$ & Nisa & 29.76 & 1.01 & 0.034 & & & & & & \\
\hline & BSUTH & 20.33 & 2.41 & 0.119 & 0.29 & 0.39 & 0.34 & 21.35 & -9.19 & 6.08 \\
\hline
\end{tabular}

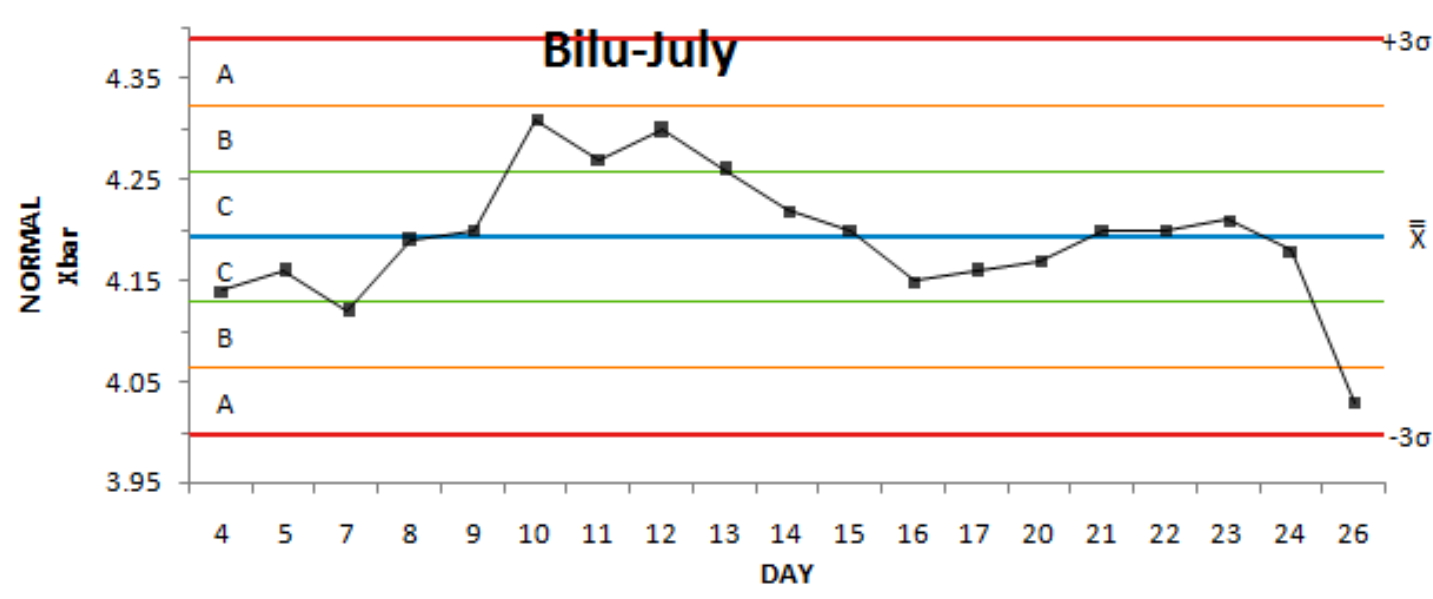




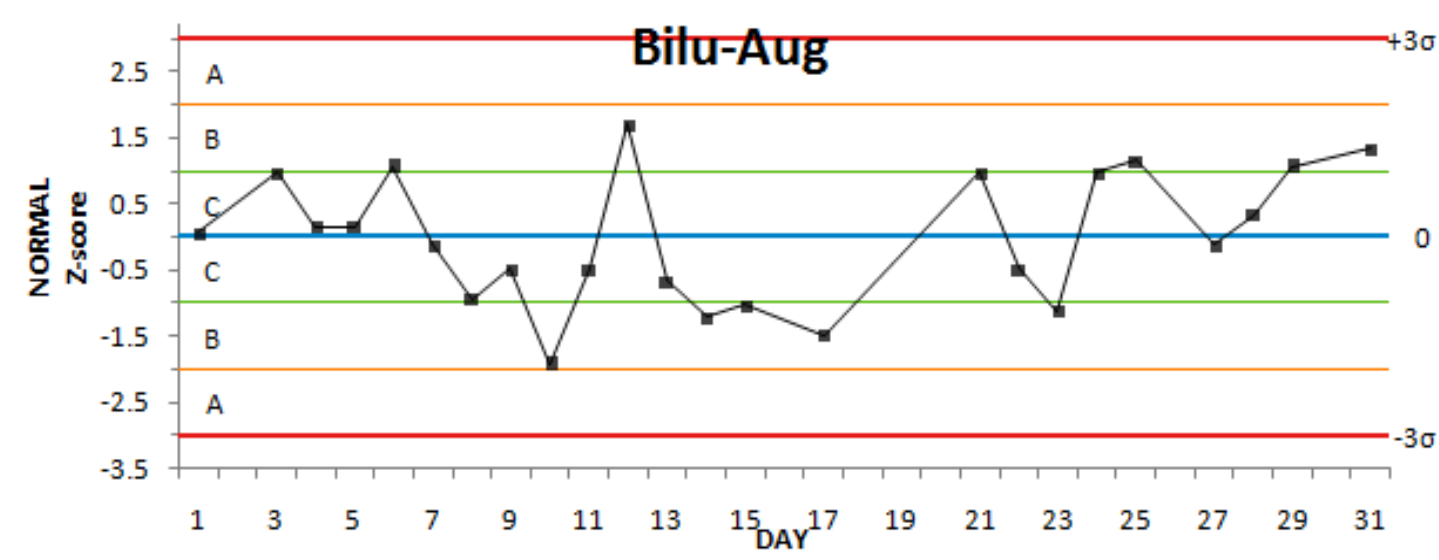

Figure1. QC charts for Bilirubin
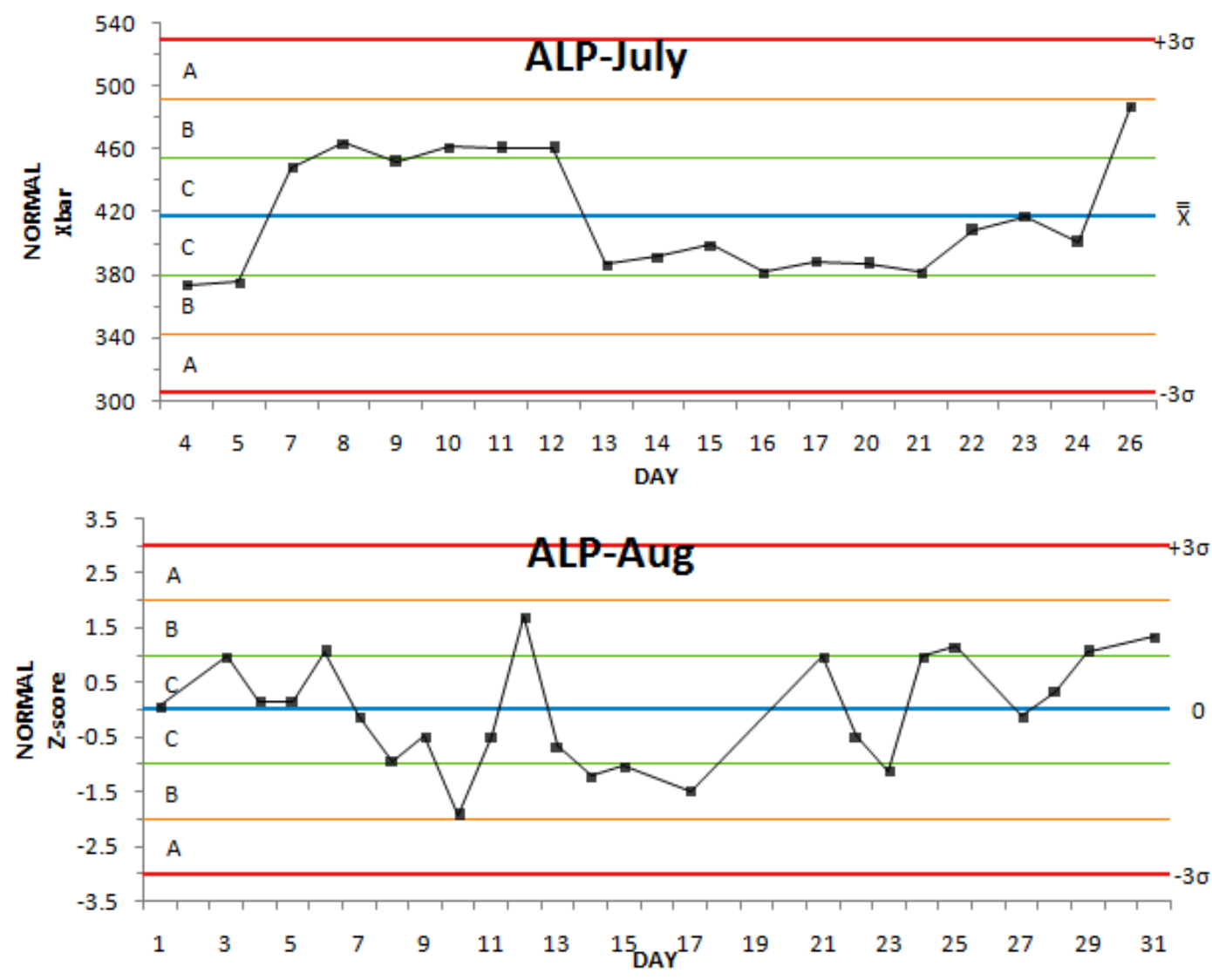

Figure2. QC charts for Alkaline Phosphates-ALP July/August 2016

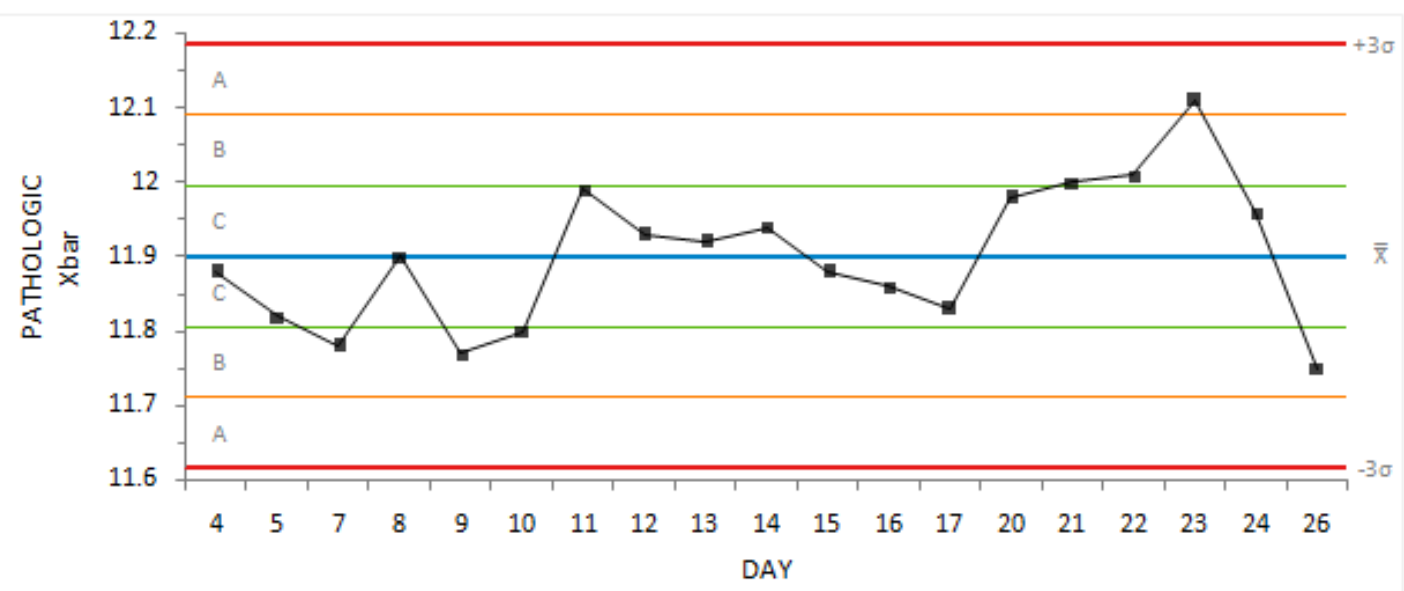


Quality Control Monitoring \& Evaluation of Bilirubin, Alkaline Phosphates and Inter-Laboratory Assessment of two Hospitals in North Central Nigeria

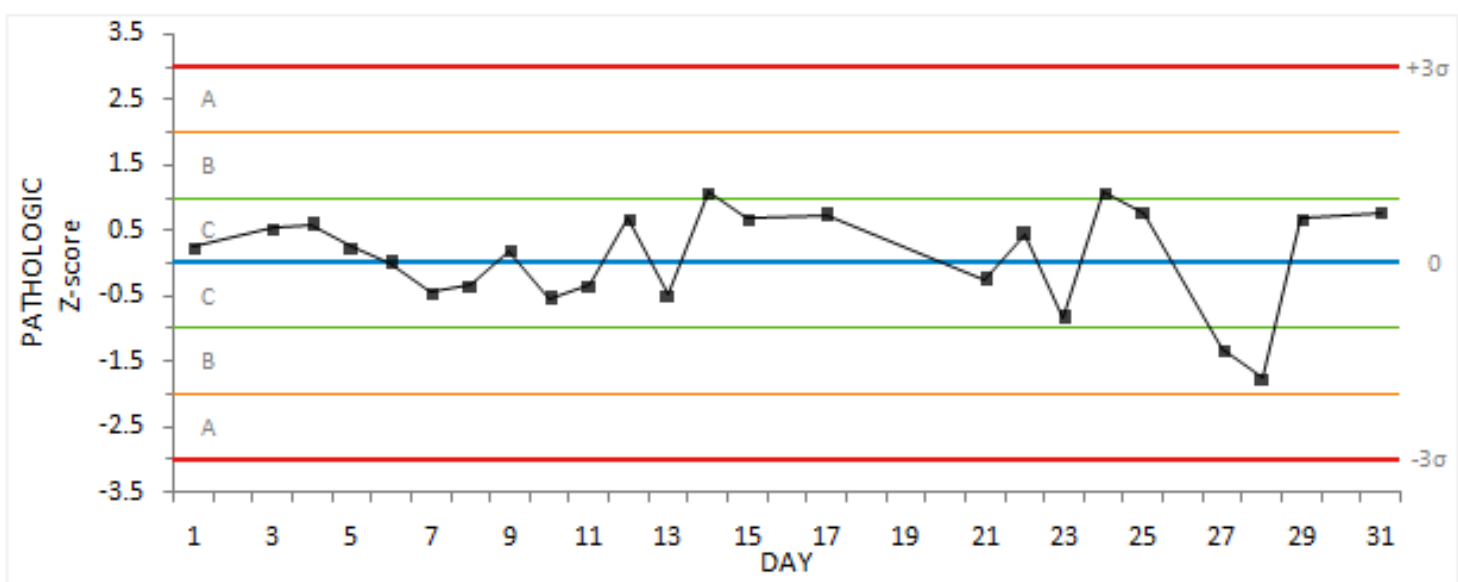

Figure3. Pathologic Bilirubin QC charts July/Aug 2016
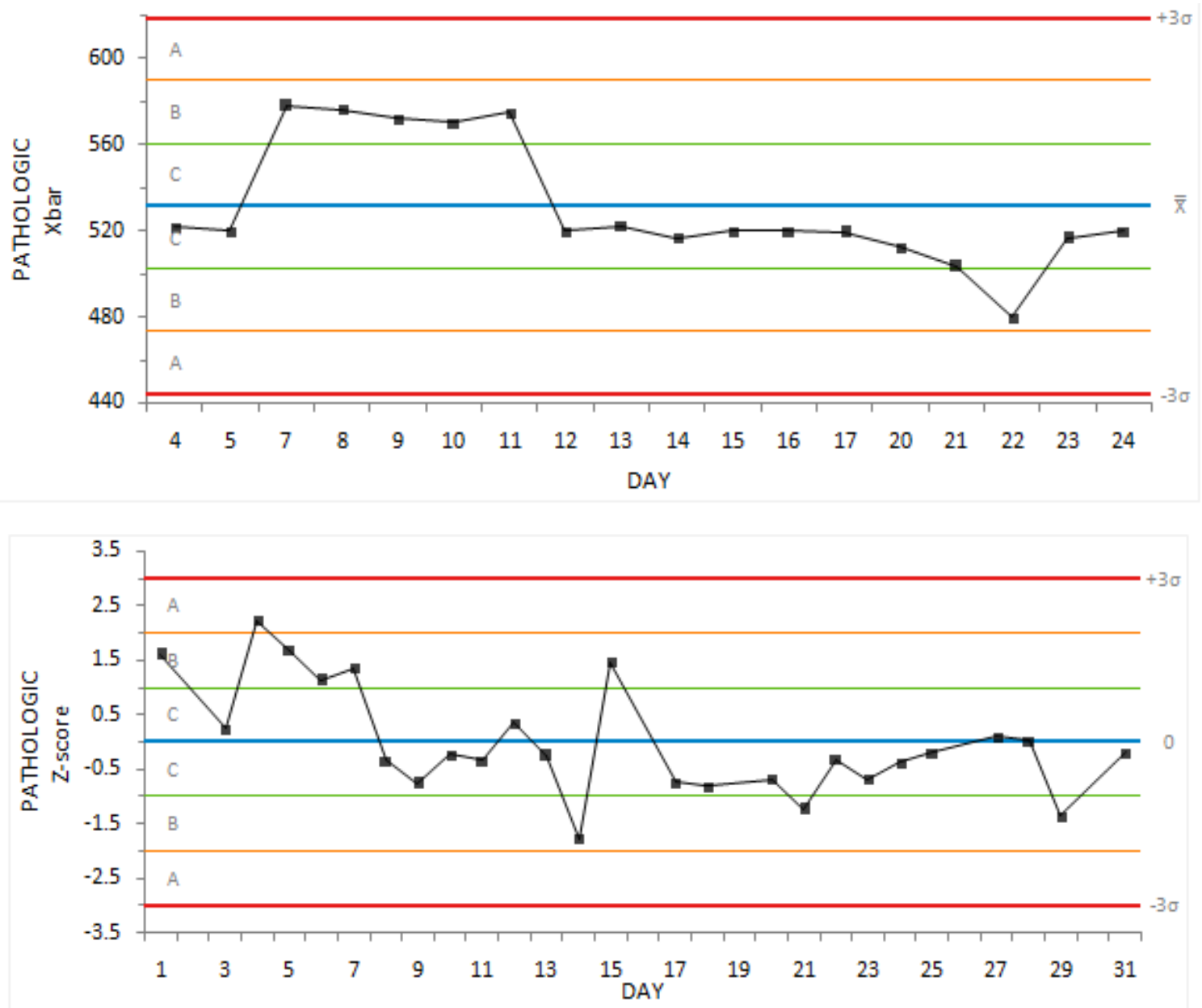

Figure4. Pathologic Alkaline phosphates -ALP QC charts July/Aug 2016

\section{DISCUSSION}

Trends (loss of reliability) and shifts (abrupt changes in the control mean) [15] were noted in the results of this study, there were two major trends in July and more shifts in the month of August than in the month of July for bilirubin and two violations of the Westgard Rule for Alkaline phosphates, two control values were out of control and violated the $1_{2} \mathrm{~s}$ Westgard rule for both bilirubin and Alkaline phosphates in the month of July and August for normal and pathological controls and this indicate a smaller systematic error. The internal quality control is a key technical requirement through accreditation by the NF EN ISO 15189. This document presents recommendations to assist the medical laboratory to design, implement and operate daily and retrospectively an efficient system of internal control quality. It identifies the important issues attached to these different steps [16].In this 
study many warning signs were recorded, it is not completely unusual but in the course of the study the laboratories had to introduce unusual attempts to bring their system in control. These violations typically identify smaller systematic error oranalytical bias that is not often clinically significant or relevant. Analytical bias may be eliminated by performing calibration or instrument maintenance.[15]

The result of interlaboratory study for electrolytes analyses (Table 1) shows a great difference in the mean values of $\mathrm{K}^{+}$between the laboratories in Nisa (3.29 \pm 0.40$)$ and BSUTH $(12.23 \pm 4.65)$ but imprecision was within acceptable performance. With CVR ranges between 0.27- 0.39, and the average CVR of $0.28-.39$, with CVR $<1$, this is similar for all other analytes $\left(\mathrm{Na}^{+}, \mathrm{TCO}_{2}{ }^{-}\right)$, with exception of $\mathrm{Cl}^{-}$which clearly indicated "Marginal performance"; as $1<\mathrm{CVR}<1.5$, requiring corrective action to be taken for both laboratories in terms of measurement imprecision. The high concentrations of chloride may be due to patients factor such as loss of body fluids (dehydration), kidney failure or disorders, diabetes insipidus, drugs such as androgens, corticosteroids, estrogens, and faulty instrumental calibration. Bias was obvious between both laboratories for electrolytes parameters. All values were either SDI $>1.5$ or SDI $<-1.5$, similarly at Marginal performance; requiring corrective action. [17]

Álvarez etal revalidated (ISO 15189 standard) some different colorimetric methods for $\mathrm{Mg}$ determination in serum used in clinical and/or biochemical laboratories in four hospitals in Spain, on the basis of results of interlaboratory comparison programmes: Bio-Rad External Quality Assurance (EQAS) and external quality control Statistical External Quality Control (SEQC). Precision and inaccuracy were estimated by analysis of records of an external quality control programme for $\mathrm{Mg}$. The precision and inaccuracy values obtained were both less than $10 \%$, except in one hospital in which the precision was less than $15 \%$. These values of precision and inaccuracy obtained may be considered highly satisfactory taking into account the validation requirement for these ones less than $10 \%$. Their findings demonstrate the effectiveness of the new revalidation methodology for diagnostic methods in medicine, which does not require any disruption of the laboratory's routine activity and which can be used even if the method in question has not been validated previously. They also suggested that the ideas and requirements of ISO 15189 should be followed by the research laboratories [18].The results of this study is very essential for the wellbeing of the patients in north central Nigeria as Laboratory quality control is designed to detect, reduce, and correct deficiencies in a laboratory's internal analytical process prior to the release of patient results, in order to improve the quality of the results reported by the laboratory.

\section{CONCLUSION}

In this study warning signs were recorded, it is not completely unusual these violations typically identify smaller systematic error oranalytical bias that is not often clinically significant or relevant.The results of the study shows that both imprecision and bias exist between both laboratories, indicating corrective action to be taken for both laboratories in terms of measurement imprecision.

\section{ACKNOWLEDGEMENT}

Authors acknowledge the support of all the stafff of both laboratories and the Health Research \& Ethics Committee of Nisa Hospital Abuja and Benue State University Teaching Hospital, Makurdi, Nigeria.

\section{REFERENCES}

[1] Hund, E., Massart, D.L,and Smeyers-Verbeke, J. (2000). Inter-laboratory studies in analytical chemistry. Analytica Chimica ActaVol 432. p. 145-65.

[2] Tietz, N.W. (1987). "Fundamentals of Clinical Chemistry", Third Edition, W.B. Saunder Company.

[3] Grant, E.L. and R.S. Leavenworth (1988). "Statistical Quality Control", Sixth Edition, McGraw-Hill Book Company

[4] Westgard, J.O. (2010). Managing quality vs. measuring uncertainty in the medical laboratory. Clinical Chemistry and Laboratory Medicine.vol 28 p. 31-40

[5] Westgard, J.O., P.L. Barry, and M.R. Hunt (1981). "A Multi-rule Shewhart Chart for Quality Control in Clinical Chemistry," Clinical Chemistry, vol. 27, pp. 493-501.

[6] Westgard, J.O., P.L. Barry (1986). "Cost-Effective Quality Control: Managing the Quality and Productivity of Analytical Processes" AACC Press. 
Quality Control Monitoring \& Evaluation of Bilirubin, Alkaline Phosphates and Inter-Laboratory Assessment of two Hospitals in North Central Nigeria

[7] Vítek L, Ostrow JD. Bilirubin chemistry and metabolism; harmful and protective aspects. Curr Pharm Des. 2009; 15 (January 2016): 2869-83

[8] Wang X, Chowdhury JR, Chowdhury NR. Bilirubin metabolism: Applied physiology. Vol.16, Current Paediatrics. 2006. p. 70-4.

[9] Fevery J. Bilirubin in clinical practice: A review. Vol. 28, Liver International. 2008. p. 592-605.

[10] Cheifetz, Adam S. (2010). Oxford American Handbook of Gastroenterology and Hepatology. Oxford: Oxford University Press, USA. p. 165

[11] Audu I. Stephen, Simon T. Ubwa, Ogbene G. Igbum, Stephen S. Hati, Analytical Methods Comparison for the Determination of Bilirubin in Blood Samples of Neonates, Advances in Analytical Chemistry, Vol. 7 No. 1, 2017, pp. 1-6.

[12] American Association of clinical chemistry(2016): Alkaline Phosphates (ALP)

[13] Syzdek J, Borkowska R, Perzyna K, Tarascon JM, Wieczorek W (2007). "Novel composite polymeric electrolytes with surface-modified inorganic fillers". Journal of Power Sources.173 (2): 712-720..

[14] Analyse-it. Analyse-it v.4.6 (2015). Clinical and Analytical Method Validation Statistical Software for Microsoft Excel. Analyse-it Software, Ltd. Leeds, United Kingdom.

[15] Greg Cooper. (2008). Basic Lessons in Laboratory Quality Control Basic Lessons in Laboratory Quality Control. Bio-Rad Laboratories, Inc. 38. UNIDO. Complying with ISO 17025: A practical guide book for meeting the requirements of laboratory accreditation schemes based on ISO 17025:2005 or equivalent national standards. Vienna; 2009.

[16] Giroud, C., Arnaud, J., Adjidé, V. and Vassault. (2010). Internal quality control. Vol. 68, Annales de biologie clinique. p. 203-21.

[17] Carstensen, B. (2010). Comparing clinical measurement methods : a practical guide. John Wiley \& Sons.

[18] Álvarez, S.I, García A.B, Martínez S.O, González MDF, Revaldería JG and De Jalón Comet Á.G. (2008) Estimation of precision and inaccuracy for serum magnesium determination on the basis of interlaboratory comparison data Accreditation ISO 15189. Magnes Res.;21(1):51-7.

Citation: S. I. Audu et al., "Quality Control Monitoring \& Evaluation of Bilirubin, Alkaline Phosphates and Inter-Laboratory Assessment of two Hospitals in North Central Nigeria", International Journal of Clinical Chemistry and Laboratory Medicine (IJCCLM), vol. 3, no. 3, pp. 1-7, 2017. http://dx.doi.org/10.20431/24557153.0303001

Copyright: (C) 2017 Authors. This is an open-access article distributed under the terms of the Creative Commons Attribution License, which permits unrestricted use, distribution, and reproduction in any medium, provided the original author and source are credited. 